\title{
Visión autoral/vision figural: una mirada desde la narratología y fenomenología
}

\section{Luz Aurora Pimentel}

La autora establece vínculos entre la teoría narrativa y la filosofía de la percepción de Merleau-Ponty. En el modelo de la situación narrativa autoral, situación narrativa figural, y narración en primera persona, muestra refracción del punto de vista sobre el mundo representado de acuerdo con la relación entre la voz narradora y el sujeto de la mediación. Los ejemplos se toman de Balzac y Dickens.

The author establishes links between narrative theory and Merleau-Ponty's philosophy of perception, in the context of the following models: authorial narrative situation, figured narrative situation and first person narration. The author shows how the point of view on the represented world refracts according to the narrative voice and what she names the subject of mediation. The examples are taken from Balzac and Dickens. 

Luz Aurora Pimentel

Universidad Nacional Autónoma de México

\section{Visión autoral / visión figural: una mirada desde la narratología y la fenomenología}

El juego de contar ya está incluido en la realidad contada Paul Ricoeur

No hay visión sin pensamiento. Pero no basta pensar para ver: la visión es un pensamiento condicionado Maurice Merleau-Ponty

Un relato verbal, oral o escrito, es la proyección de un mundo de acción humana. Tal proyección, sin embargo, no es tan sólo una "representación" neutra, un ilusorio "reflejo fiel" de lo representado, sino, como diría Ricoeur, una redescripción de la realidad. ${ }^{1}$ Más aún, el acto de redescripción se nos presenta como un acto orientado y mediado por un punto de vista sobre el mundo, pues si hay un rasgo definitorio del modo narrativo ese es el principio de la mediación (cf. Stanzel 1984, 4-21). Aun cuando la estructura profunda de otras formas de representación de la acción humana, tales como el drama, la pintura, la mímica, o la tira cómica, pueda ser definida como una estructura narrativa —específicamente semionarrativa-, aun cuando por ello se pueda considerar al narrador como una figura optati-

${ }^{1}$ Cf. Paul Ricoeur, "Métaphore et référence", en 1975, y "The Function of Narrative", en 1981. 
va, un relato verbal, stricto sensu, implica necesariamente un sujeto de la enunciación: alguien que cuente algo a alguien. Estos ingredientes básicos de la enunciación narrativa son la condición misma que funda al relato verbal.

Ahora bien, la redescripción mediada de la realidad es un efecto de sentido que depende directamente de las formas de organización narrativas y descriptivas a las que el autor recurre para construir el mundo del relato y que se proponen como un equivalente de nuestra experiencia de la realidad. Estas formas de organización descriptivas y narrativas proyectan significaciones de orden sensorial que a veces hacen eco de la reflexión filosófica sobre las diversas formas de percibir al mundo. A lo largo del análisis narrativo que habré de llevar a cabo, aunque muy de vez en cuando, intentaré hacer sonar algunas de esas cuerdas afines para proponer una resonancia entre teoría narrativa y reflexión filosófica. En especial acudiré a la obra de Merleau-Ponty que tanto parece decir - aunque nunca se refiera a ellas - sobre formas narrativas de la percepción, y sobre el efecto del relato en el lector como otra manera de percibir el mundo, una especie de "sensible en segundo grado".

Un relato, entonces, es una redescripción del mundo mediada por un punto de vista sobre el mundo. No obstante, ese sujeto de la mediación que es el narrador, no necesariamente coincide con la perspectiva, la cual opera como filtro y como principio organizador de la redescripción de la realidad. De ahí que sea posible identificar, con Franz Stanzel, tres situaciones narrativas básicas: narración autoral, narración figural y narración en primera persona.

En la situación narrativa autoral, el sujeto de la mediación y la perspectiva narrativa coinciden plenamente; el mundo se mira desde los ojos, desde los juicios y prejuicios de un narrador, es decir del sujeto de la mediación que Stanzel equipara al autor. De hecho sería más justo hablar de una situación narrativa narratorial, pero por comodidad y eufonía habré de mantener 
el término autoral, sin que por ello perdamos de vista el hecho de que no se puede confundir en un relato al autor con el narrador.

En la situación narrativa figural, el sujeto de la enunciación sigue siendo el narrador pero el punto de vista que organiza la presentación del mundo narrado no es la suya sino la de algún personaje. Puesto que ese personaje focal existe como "reflector" de la realidad representada, y que desde el punto de vista de la enunciación el personaje se presenta como un desdoblamiento del sujeto que percibe, piensa y "dice" al mundo, bien podría considerarse esta conciencia ficcional, diferente de la del sujeto que narra, como una verdadera figura narrativa. De ahí que una situación narrativa figural implique un desdoblamiento y una escisión: alguien narra, sí, mas no es su punto de vista el que orienta la selección de lo narrado sino la perspectiva de otra conciencia. ${ }^{2}$

En la narración en primera persona parecería haber, a primera vista, una convergencia entre la perspectiva que orienta la narración y la voz que narra. Stanzel lo propone de ese modo; afirma que

es característico de la situación narrativa en primera persona el hecho de que la mediación de la narración pertenezca totalmente al mundo ficcional de los personajes de la novela: el mediador, es decir, el narrador en primera persona, al igual que los demás personajes, es él mismo un personaje de este mundo. El mundo de los personajes es totalmente idéntico al del narrador". 3

${ }^{2}$ El trabajo de Genette ha sido seminal en el deslinde conceptual necesario entre la voz que narra y la perspectiva que orienta la narración; es decir, una distinción entre voz y perspectiva narrativas. Ver "Discours du récit", en 1972, y 1983.

3 "It is characteristic of the first-person narrative situation that the mediacy of narration belongs totally to the fictional realm of the characters of the novel: the mediator, that is, the first-person narrator, is a character of this world just as the other characters are. The world of the characters is completely identical to the world of the narrator" (Stanzel 1984, 4). A menos que se indique otra cosa, la traducción de textos teóricos es mía. 
Difiero en este punto de estudioso alemán, pues un análisis más fino de esta situación narrativa en primera persona nos revela un desdoblamiento del sujeto que acusa un grado de complejidad aún mayor que en la situación narrativa figural. ${ }^{4}$ Cierto es que ese "yo" que identifica al sujeto de la enunciación es ontológicamente el mismo que el "yo" cuyas vicisitudes narra. Pero aun cuando el sujeto sea la misma "persona", narrativamente se desdobla en sujeto y objeto: ${ }^{5}$ en tanto yoque-narra, el sujeto se toma a sí mismo en el pasado como objeto de su acto narrativo, y ambas funciones, vocal y diegética, lo escinden y lo colocan en distintos mundos: el yo-que-narra, qua narrador, opera en un mundo que, si bien fue, ya no es el mundo narrado. El yo-que-narra habita el mundo del acto de narrar, mientras que el yo-narrado habita el mundo de acción humana que va construyendo la narración. De ahí que el narrador en primera persona pueda asumir o bien su propia perspectiva como narrador y en el momento de la narración, o bien una perspectiva que bien podríamos llamar autofigural, ajustándose a las restricciones de orden espacial, temporal, cognitivo y perceptual de su yo-narrado.

Es interesante observar ciertas tendencias en la narrativa occidental con respecto a estas formas de presentación. En una situación narrativa autoral, el narrador tiende a describir

\footnotetext{
${ }^{4}$ Habré de utilizar los términos de Stanzel haciendo algunas precisiones y discrepando del teórico alemán en ciertos puntos. En el caso del término figural, Stanzel en ningún momento define la conciencia del personaje como una escisión entre el origen vocal y el focal de la información narrativa. Respecto al término figural en sí, es posible extender su significación en analogía con las figuras de la retórica. Esta, sin embargo, no es consideración de Stanzel, sino una reflexión mía sobre el fenómeno del desdoblamiento del sujeto en un relato, y, de manera muy especial, en un relato de ficción, la única forma narrativa que nos da un acceso privilegiado a la conciencia de otro, diferente del que narra.

5 Ya Todorov hablaba de estos desdoblamientos del sujeto de la enunciación desde su "Qu'est-ce que le structuralisme?" (1968, 65-66): "Dès que le sujet de l'énonciation devient sujet de l'énoncée, ce n'est plus le même sujet qui énonce. Parler de soi-même signifie ne plus être le même 'soi- même'. (...) 'Je' ne réduit pas deux à un mais de deux fait trois".
} 
el mundo no como algo que él, en tanto que sujeto, percibe, sino como una estructura exterior, "objetiva" y "colectiva", es decir, como algo que se puede compartir, que se podría, incluso, constatar. Así pues, desde la perspectiva autoral, el mundo narrado aparece como un mundo pensado y compartido, organizado a partir de modelos de saber "autorizados", exteriores al texto, y que pertenecen a una suerte de enciclopedia del saber de una época dada.

La práctica textual privilegiada para construir esa imagen del mundo es lo que se conoce como descripción. ${ }^{6}$ Una descripción, definida elementalmente como la puesta en equivalencia de un nombre y una serie predicativa (cf. Hamon 1972, 465-485, y 1981), recurre a modelos de organización discursiva que permiten combinar de una manera y no de otra los diversos elementos de la serie predicativa: entre muchos otros podrían mencionarse los modelos lógico-lingüísticos de espacialidad, los modelos taxonómicos provenientes del discurso del saber oficial, o modelos culturales de todo tipo - la pintura, la arquitectura, incluso la música pueden ser utilizados como esquemas en la organización de la descripción de un lugar, un objeto o una persona-. Por ejemplo, para la proyección realista del espacio diegético y de los objetos que en él se distribuyen se recurrirá, necesariamente, a modelos binarios de espacialidad basados en categorías lógico-linguiísticas tales como cercano/lejano, arriba/abajo, dentro/fuera, frente a/detrás de, etc., ${ }^{7}$ o bien al modelo tridimensional de espacialidad que destaca Greimas (1979, s.v. dimensionnalité): horizontali$\mathrm{dad} /$ verticalidad / profundidad.

${ }^{6}$ El marco teórico de esta sección, antes del análisis de un pasaje de Great Expectations, de Dickens, está tomado de mi libro, El espacio en la ficción (2001, 59-68)

${ }^{7}$ Cf. Jean Weisberg (1978, 15,17-18). Weisberg incluye otras categorías tales como la forma, el movimiento, la comunicación, la continuidad, el conjunto, la separación, etc., que se articulan, nuevamente en oposiciones binarias. 
A pesar de la fuerte ilusión de espacialidad que produce un relato, estrictamente hablando una descripción no crea un verdadero espacio, sino que produce un espacio significado, es decir, un espacio lógico. Algo semejante ocurre con el objeto descrito. De él sólo queda el residuo que los modelos elegidos, como tantos filtros o cribas, permiten pasar. Uno de los modelos básicos para organizar la descripción de un mundo poblado de objetos es el de las cuatro variables que Foucault abstrae como el punto de partida de la historia natural:

Observar significa, entonces, contentarse con ver. Con ver sistemáticamente pocas cosas. Con ver, en la riqueza un poco confusa de la representación, aquello que pueda ser analizado, que pueda ser reconocido por todos, y recibir así un nombre que cualquiera pueda entender[...] [El objeto de la historia natural] es la extensión de la que están constituidos los seres de la naturaleza — extensión que se puede afectar con cuatro variables-. Y cuatro variables solamente: la forma de los elementos, la cantidad de esos elementos, la manera en que se distribuyen en el espacio unos con respecto a otros, y el tamaño relativo de cada uno (Foucault 1966, 146). ${ }^{8}$

Así, al igual que la representación del espacio, la de los objetos también se reduce a categorías, gracias a los modelos lógicos más utilizados. Con frecuencia se sobrepone a este modelo de las cuatro variables - forma, cantidad, tamaño y distribución en el espacio- el de los sentidos; de tal manera que las categorías lógicas se combinan con las sensibles para dar cuenta de un objeto: color, textura, olor, sabor, sonoridad

8 “'Observer, c'est donc se contenter de voir. De voir systématiquement peu de choses. De voir ce qui, dans la richesse un peu confuse de la représentation, peut s'analyser, être reconnu par tous, et recevoir ainsi un nom que chacun pourra entendre [...] [l'objet de l'histoire naturelle] c'est l'étendue dont sont constitués les êtres de la nature —étendue qui peut - être affectée de quatre variables. Et de quatre variables seulement: forme des éléments, quantité, de ces éléments, manière dont ils se distribuent dans l'espace les uns par rapport aux autres, grandeur relative de chacun." 
(si es que la tiene). De cualquier manera, el objeto se construye, como dijo Barthes (1970, 67-68), en bloques de sentido que se apiñan y traslapan creando efectos de sentido acumulativo; todo esto, claro está, cribado por el modelo o los modelos que organizan la descripción.

El sistema descriptivo aparece entonces como un universo de discurso estructurado según uno o varios modelos, ya sea linguísticos (composición semántica que resulta en un sistema potencial de contigüidades obligadas), lógico-lingüísticos (categorías espaciales que se resuelven en oposiciones binarias, tales como arriba/abajo, cerca/lejos, dentro/fuera, etc.), o modelos extratextuales, provenientes de otros discursos del saber oficial y/o popular, tales como el de los sentidos, las taxonomías científicas o populares, los modelos de organización urbana, o bien modelos provenientes de otras artes (arquitectura, pintura, música).

La descripción, y en especial la descripción realista del espacio, no se concibe sin todos estos modelos; no podría crear sin ellos la ilusión de lo real. Y es que los discursos de saber (y, con frecuencia, los de poder) son los que previamente han organizado nuestra percepción de la realidad. Como bien lo ha observado Hamon,

la descripción es [...] meta-clasificación, es texto de clasificación que clasifica y organiza una materia ya segmentada por otros discursos [...] Antes de clasificar al mundo, antes de ser escritura del mundo, la descripción es reescritura de otros sistemas de clasificación. Reticulación textual, reticulación del léxico, ante todo la descripción es reticulación de un extratexto (clasificaciones, discursos enciclopédicos, vocabularios especializados, los diversos textos del saber oficial sobre el mundo, categorías ideológicas) ya reticulado y racionalizado $(1981,57-61){ }^{9}$

9 "La description [...] est méta-classement, est texte de classement classant et organisant une matière déjà découpée par d'autres discours (57) [...] Avant de 
Es por ello que si una descripción se adecua a esos modelos producirá la ilusión de objetividad, la ilusión de que el espacio construido "embona", ficcionalmente, en el construido culturalmente, el espacio "real" de nuestro mundo cotidiano. De ahí que, paradójicamente, una proyección realista del mundo esté doblemente mediada: por la perspectiva del descriptor-narrador y por el punto de vista que implican los diversos discursos del saber oficial a los que recurre para organizar su descripción y producir ese efecto de lo real.

Observemos ahora más de cerca este fenómeno de construcción textual que es la descripción "objetiva" de un lugar, acudiendo a un texto de Balzac: la descripción del cuarto de d'Arthez en Las ilusiones perdidas.

La habitación de Daniel d'Arthez, situada en el quinto piso, tenía dos destartaladas ["méchantes"] ventanas entre las que había una estantería de madera ennegrecida, llena de cajas con marbetes. Una mezquina ["maigre"] camita de madera pintada, semejante a los lechos de un dormitorio de colegio; una mesilla de noche comprada de ocasión, y dos butacas forradas de crin ocupaban el fondo de la habitación cuyas paredes estaban cubiertas con un papel escocés barnizado por el humo y por el tiempo. Entre la chimenea y las dos ventanas había una larga mesa cargada de papeles. Frente a la chimenea se encontraba una mala cómoda de madera de caoba. El suelo estaba cubierto por completo por una alfombra comprada de segunda mano. Este lujo necesario ahorraba la calefacción. Un vulgar sillón de despacho, con el asiento y el respaldo forrados de badana roja que se había vuelto blanca por el uso, colocado ante la mesa, y seis sillas desportilladas ["mau-

classer le monde, d'être écriture du monde, la description classe d'autres systèmes de classement, est réécriture d'autres systèmes de classement. Réticulation textuelle, réticulation du lexique, la description est d'abord réticulation d'un extra-texte (classifications, discours encyclopédiques, vocabulaires spécialisés, textes divers du savoir officiel sur le monde, catégories idéologiques) déjà réticulé et rationalisé" (61). 
vaises"] completaban el mobiliario (Balzac, Las ilusiones perdidas, 1956, VII, 417-418). ${ }^{10}$

El incipit de esta descripción lo constituye el anuncio del tema: "la habitación de Daniel d'Arthez". Al mismo tiempo, el anuncio del tema sirve también para dar una visión de conjunto del objeto a describir, movimiento generalizante que habrá de repetirse con la frase que clausura la descripción: “...seis sillas desportilladas completaban el mobiliario". Las partes constitutivas del tema propuesto acusan una fuerte previsibilidad léxica. Y es que el sistema de contigüidades obligadas inherente a este tema descriptivo —-/habitación/— genera lo que podríamos llamar una isotopía descriptiva que nunca se rompe. Ninguno de los elementos descritos queda fuera de este sistema: en cuanto al amueblado los subtemas cama, mesa, sillas, sillones, butacas; en cuanto a la habitación como espacio doméstico construido, las partes descritas también son previsibles: ventanas, paredes, suelo, chimenea, etc.

La serie predicativa que nos "pinta" esta habitación está doblemente configurada: la forma paratáctica del inventario (cama, mesa, sillas, butacas...) se ve modulada tanto por los sistemas lógico-lingüísticos que la organizan en espacio significado, como por predicaciones que articulan ideológicamente la significación del espacio representado. Comencemos por el modelo de espacialidad que rige esta descripción. Así como el tema se anuncia al principio para dar una visión de conjunto, de

10 "La chambre de Daniel d'Arthez, située au cinquième étage, avait deux méchantes croisées entre lesquelles était une bibliothèque en bois noirci, pleine de cartons étiquetés. Une maigre couchette en bois, peint, semblable aux couchettes de collège, une table de nuit achetée d'occasion, et deux fauteuils couverts en crin occupaient le fond de cette pièce tendue d'un papier écossais verni par la fumée et par le temps. Une longue table chargée de papiers était placée entre la cheminée et l'une des croisées. En face de cette cheminée, il y avait une mauvaise commode d'acajou. Un tapis de hasard couvrait entièrement le carreau. Ce luxe nécessaire évitait du chauffage. Devant la table, un vulgaire fauteuil de bureau en basane rouge blanchie par l'usage, puis six mauvaises chaises complétaient l'ameublement" (Balzac 1966, 222-223). 
la misma manera se nos ofrece una ubicación espacial general de esta habitación: en el quinto piso del edificio. Luego se procede a describir la habitación echando mano de categorías lógico-lingüísticas, con el propósito de ir dando la ubicación precisa (la ilusión de precisión tan cara siempre a Balzac) de cada objeto descrito en relación con los demás: la estantería está situada "entre" las dos ventanas; la serie constituida por cama, mesa de noche y butacas, queda ubicada "al fondo" de la habitación; la mesa "entre" la chimenea y las dos ventanas; la cómoda "frente a" la chimenea, etc., de tal modo que casi se podría hacer un diagrama de esta habitación y de la relación que en ella se establece entre los objetos que la amueblan. Otras relaciones espaciales de tipo local quedan precisadas también con la ayuda de estas mismas categorías, aunque de manera implícita: los papeles "sobre" la mesa ("cargada" de papeles), las cajas "dentro" de la estantería ("llena de cajas"). Como podrá observarse, la deixis de referencia espacial, es decir, el punto cero del espacio en esta descripción, no es necesariamente fijo sino que varía; cada una de las partes descritas, casi como en relevo, va constituyendo la deixis de referencia a partir de la cual se ubica el siguiente objeto: si "ocupaban el fondo de la habitación" sugiere la puerta de entrada como punto de referencia, la descripción de la mesa y de la cómoda se organiza en torno a la chimenea, la cual funge entonces como la deixis de referencia que organiza esa parte de la descripción.

Además del inventario del amueblado y de las partes constitutivas de la habitación, reticulados por modelos de espacialidad lógico-linguíísticos, el modelo lógico de las cuatro variables, aunado al de los sentidos, va calificando y particularizando cada objeto descrito: se nos precisa la cantidad para cada objeto — una cama, seis sillas, dos butacas, etc._- el tamaño - "una mesa grande"- Se especifican los colores de muchos de ellos — "ennegrecido", "roja", "blanqueada"-; los materiales de que están hechos o forrados — "de caoba", "de badana roja", "de crin"-. 
Parecería como si la descripción de esta habitación fuera tan "fidedigna" que no hubiera en ella artificio alguno. Pero esto es sólo una ilusión generada por aquella práctica textual, especialmente artificial debido al alto grado de codificación retórica, que es la descripción. Incluso la supuesta objetividad es relativa, pues de hecho lo que llama más la atención es la selección de adjetivos que califican a casi todos los objetos de manera subjetiva o moral, y que son tan numerosos - si no es que más- que los adjetivos que nos dan una visión "objetiva" (en especial los que dan cuenta de la forma, tamaño, color, textura, cantidad, etc., del objeto descrito): las ventanas son "méchantes" ("malas" o "desagradables"); la cama "maigre" ("mezquina", pero el adjetivo, que se abre al espacio de la figura retórica de la hipálage, se proyecta, asimismo, de manera antropomórfica a su ocupante, d'Arthez, quien también debe ser flaco); la mesa de noche, como la alfombra, son de segunda mano; la cómoda es "mauvaise" ("mala"), aunque sea de caoba, y el mismo adjetivo califica a las sillas; el sillón, finalmente, es "vulgar". Si el sistema de contigüidades obligadas, que tiene como efecto una previsibilidad léxica, construye una especie de isotopía descriptiva, la serie de adjetivos que connotan la miseria de d'Arthez generan una isotopía tonal. Por una parte estos adjetivos serían el punto de articulación de significaciones simbólicas más vastas (la miseria "decente" de d'Arthez, quien encarna los mejores valores morales en esta novela, se contrapondrá a la miseria "sórdida" de Lousteau, quien a su vez encarna los peores vicios); por otra parte, estos mismos adjetivos actúan como operadores tonales, cuya redundancia semántica traza la isotopía tonal disfórica que unifica toda la descripción.

Un último instrumento de verosimilización es el sistema de referencias a códigos culturales compartidos. Como los otros sistemas examinados, éste contribuye a generar esa ilusión de perfecta adecuación entre el universo diegético y el mundo real —o, como diría Eco $(1981,185)$, "el mundo 'real' de la 
enciclopedia del lector"- enciclopedia que un narrador como los de Balzac supone siempre ser idéntica a la del autor y a la de muchos otros lectores. Aun cuando en el pasaje arriba citado sean escasas esas referencias, no por ello son menos significativas: al describir la cama, la sola analogía remite —o por lo menos remitía a sus contemporáneos- a una realidad compartida por todos y que se caracteriza por su estrechez e incomodidades: "semejante a los lechos de un dormitorio de colegio", o bien la descripción de la mesa de noche y de la alfombra activa un código cultural compartido que haría de estos objetos algo reconocible: la mesa "comprada de ocasión", la alfombra "comprada de segunda mano".

Todos los modelos empleados en este complejo sistema descriptivo intentan construir un espacio humano que dé la ilusión de embonar perfectamente en el de la realidad extratextual. La "adecuación" a la "realidad" queda propuesta aquí como la autoridad última e incuestionable a la que el texto realista apelará como garantía de verdad y de autenticidad; declarará exitosa la empresa cuando el universo diegético sea un "fiel reflejo" del mundo. Desde nuestra perspectiva, sin embargo, la descripción crea una ilusión de realidad gracias a que se conforma, no a la realidad, sino a los modelos de realidad construidos por otros discursos y que influyen en nuestra percepción del mundo.

No obstante, es importante hacer notar que aun en descripciones que se quieren "objetivas" como ésta de Balzac, la selección de ciertos calificativos introduce un grado de subjetividad considerable y constituyen el punto de articulación ideológica de esta redescripción de la realidad. Mas la vocación balzaciana de objetividad es tan fuerte que incluso la subjetividad de los valores atribuidos a los lugares, los objetos o las personas, queda asimilada a sistemas de valores colectivos, dándole así una sanción de consenso y, por ende, de objetividad. De ahí que la propia subjetividad acabe formando, 
mañosamente, parte del proyecto de una representación supuestamente objetiva del mundo.

Ahora bien, si la descripción autoral pretende acceder al mundo como re-presentación, como copia de la realidad, como una estructura exterior objetiva y colectiva, en la situación narrativa figural, en cambio, el solo desplazamiento focal conlleva una asunción total de subjetividad. El mundo significado de esta manera podría caracterizarse con las mismas palabras que Merleau-Ponty utiliza para describir la experiencia subjetiva del espacio:

El espacio no es más aquel de que habla la Dióptrica, red de relaciones entre objetos, tal como lo vería un tercero, testigo de mi visión, o un geómetra que la reconstruye y la sobrevuela; es un espacio contado a partir de mí mismo como punto o grado cero de la espacialidad. Yo no lo veo conforme a su envoltura exterior, lo vivo adentro, estoy englobado en él $(1986,44) .{ }^{11}$

Debido a ese grado cero de la espacialidad constituido por el sujeto que percibe, en una descripción focalizada en la conciencia de un personaje, la proyección del mundo acusa grados de distorsión con respecto a la imagen ilusoria de objetividad que propone la descripción autoral. Ahora bien, esa impresión de subjetividad, incluso de distorsión de la realidad, se resuelve textualmente en formas de organización discursiva que violentan los modelos de saber que organizan las descripciones supuestamente objetivas. En las descripciones figurales, el mundo representado deja de ser un mundo pensado, organizado y analizado lógicamente, para presentarse como un mundo

${ }^{11}$ He modificado la traducción de Romero Brest ahí donde no me parece que se apegue al sentido del original.

'L'espace n'est pas celui dont parle la Dioptrique, réseau de relations entre objets, tel que le verrait un tiers témoin de ma vision, ou un géomètre qui la reconstruit et la survole, c'est un espace compté à partir de moi comme point ou degré zéro de la spatialité. Je ne le vois pas selon son enveloppe extérieure, je le vois du dedans, j’y suis englobé" $(1964,58)$. 
percibido, un mundo in-formado, deformado y/o transformado por y a partir del cuerpo. Acudo nuevamente al filósofo. Dice Merleau-Ponty, y con razón, que "el saber científico desplaza la experiencia y que hemos desaprendido a ver, a oír y, en general, a sentir, para deducir de nuestra organización corporal y del mundo tal y como lo concibe el físico aquello que debemos oír y sentir" $(1945,265){ }^{12}$

Las formas de narración autoral sancionan y refuerzan este "desaprendizaje"; afirman un incuestionable "ser asî" del mundo y, por lo tanto, se proponen como la única forma de percibirlo. En cambio, las formas de narración figural tienden a invertir el camino, a poner en un primer plano la experiencia sensorial y sólo en un segundo momento el acto de reflexión y de análisis de la experiencia. Mas lo que aquí interesa es identificar las formas discursivas que puedan dar cuenta de esa tentativa de significar la experiencia directa o, mejor dicho, de crear la ilusión de la experiencia "ingenua", sin intervención de la reflexión.

Analizaré ahora una descripción de Charles Dickens en Grandes esperanzas, que me parece especialmente ilustrativa porque el descriptor-narrador está en primera persona, y a lo largo de la descripción constantemente se desplaza de la perspectiva de su yo-narrado a la del yo-que-narra, oscilando así constantemente entre la experiencia y la reflexión, entre el cuerpo en su relación con el mundo y el saber intelectual, reflexivo sobre ese mundo. El texto es además de especial interés por el efecto que su peculiar organización semántica y retórica produce en el lector.

[...] llamé y me contestaron desde dentro que entrase. Entré, pues, y me hallé en una habitación bastante espaciosa y bien iluminada con velas de cera. No se observaba en ella ni un

12 “ [...] le savoir scientifique déplace l'expérience et que nous avons désappris de voir, d'entendre et, en général, de sentir, pour déduire de notre organisation corporelle et du monde tel que le conçoit le physicien ce que nous devons voir, entendre et sentir" (Merleau-Ponty 1945, 265). 
solo resplandor de la luz del día. Deduje que era una alcoba, por los muebles, si bien muchos de ellos eran de forma y uso totalmente desconocidos para mí. Pero destacaba en ella una mesa vestida con un espejo dorado, e inmediatamente que lo vi decidí que era el tocador de una hermosa dama [fine lady].

No puedo afirmar, si al no haber visto allí sentada a ninguna mujer [fine lady], hubiera definido tan pronto aquel objeto. En un sillón, con el codo apoyado en la mesa y la cabeza recostada en la mano, hallábase sentada la mujer más extraña que había visto ni veré jamás.

Vestía ricas ropas - satenes, encajes y sedas-, todas blancas. Blancos eran sus zapatos. Y llevaba un largo velo blanco que le pendía del cabello, con flores nupciales en el pelo; más éste era blanco también. Algunas brillantes alhajas centelleaban en su cuello y en sus manos, y otras joyas descansaban relucientes sobre la mesa. Por todas partes había esparcidos vestidos, menos espléndidos que el que ella llevara, y baúles a medio cerrar. No había terminado de vestirse del todo, ya que sólo tenía puesto un zapato - el otro estaba sobre el tocador, cerca de ella-, el velo aún no estaba arreglado, y no se había puesto todavía la cadena ni el reloj. Algunos de los encajes de su pechero yacían junto a estas joyas, con el pañuelo, los guantes, algunas flores y el libro de oraciones, todo confusamente amontonado al lado del espejo.

Todas estas cosas no las advertí en los primeros momentos, si bien vi más de las que esperaba ver [than might be supposed]. Pero sí noté [But I saw] que todo lo que se ofrecía ante mis ojos, y que debiera ser blanco, lo había sido en un tiempo, mas había perdido su esplendor y estaba descolorido y amarillo. Vi que la novia que vestía el traje nupcial estaba tan mustia como el vestido y como las flores, y que no le quedaba otro brillo que el de sus ojos hundidos. Observé que aquel vestido se lo había puesto una figura rolliza de mujer joven, y que la persona sobre la que ahora colgaba holgadamente habíase convertido en un montón de huesos. Una vez, en la feria, habíanme llevado a ver unas espantosas figuras de cera, imagen de no sé qué imposible personaje yacente en su túmu- 
lo. Otra vez fui a nuestras viejas iglesias de los marjales a ver un esqueleto entre las cenizas de un rico vestido, enterrado en una cripta bajo el pavimento de la iglesia [that had been dug out of a vault under the church]. Ahora, las figuras de cera y el esqueleto parecían tener unos negros ojos que se movían para mirarme. Habría gritado si hubiera podido (Charles Dickens, Grandes esperanzas, II, 1477-1478). ${ }^{13}$

\section{En la primera parte de la descripción, cuando Pip, el narra- dor, nos cuenta cómo entró al cuarto de la excéntrica Miss Ha- visham, hay una interesante convergencia de perspectivas. Al}

13 “" [...] I knocked and was told from within to enter. I entered, therefore, and found myself in a pretty large room, well lighted with wax candles. No glimpse of daylight was to be seen in it. It was a dressing-room, as I supposed from the furniture, though much of it was of forms and uses then quite unknown to me. But prominent in it was a draped table with a gilded looking-glass, and that I made out at first sight to be a fine lady's dressing-table.

"Whether I should have made out this object so soon, if there had been no fine lady sitting at it, I cannot say. In an arm-chair, with an elbow resting on the table and her head leaning on that hand, sat the strangest lady I have ever seen, or shall ever see.

"She was dressed in rich materials — satins, and lace, and silks - all of white. Her shoes were white. And she had a long white veil dependent from her hair, and she had bridal flowers in her hair, but her hair was white. Some bright jewels sparkled on her neck and on her hands, and some other jewels lay sparkling on the table. Dresses, less splendid than the dress she wore, and half-packed trunks, were scattered about. She had not quite finished dressing, for she had but one shoe on - the other was on the table near her hand - her veil was but half-arranged, her watch and chain were not put on, and some lace for her bosom lay with those trinkets, and with her handkerchief, and gloves, and some flowers, and a Prayer-book, all confusedly heaped about the looking-glass.

"It was not in the first moments that I saw all these things, though I saw more of them in the first moments than might be supposed. But I saw that everything within my view which ought to be white, had been white long ago, and had lost its lustre, and was faded and yellow. I saw that the bride within the bridal dress had withered like the dress, and like the flowers, and had no brightness left but the brightness of her sunken eyes. I saw that the dress had been put upon the round figure of a young woman, and that the figure upon which it now hung loose, had shrunk to skin and bone. Once, I had been taken to see some ghastly waxwork at the Fair, representing I know not what impossible personage lying in state. Once, I had been taken to one of our old marsh churches to see a skeleton in the ashes of a rich dress, that had been dug out of a vault under the church pavement. Now, waxwork and skeleton seemed to have dark eyes that moved and looked at me. I should have cried out, if I could" (cap. 8, 46-47). 
narrar, Pip se atiene a las limitaciones de su yo-narrado, nos relata, paso a paso, cómo el niño entró a la habitación y qué fue lo primero que percibió. Desde este momento la subjetividad del niño toma las riendas de la descripción. Aunque es el narrador adulto quien evidentemente la organiza y a quien ha de atribuirse el conocimiento y la organización léxica del pasaje, es lo confuso de la impresión sensorial lo que domina la descripción como un todo.

El primer contacto con Miss Havisham es el de la brillante luz de las velas de cera, aunque el niño no deja de percibir la deliberada expulsión de la luz natural. Filtrada por esta luz artificial, se proyecta una imagen vaga de la habitación, obsesivamente focalizada en el tocador. Es interesante hacer notar que este foco de percepción-descripción borra todos los demás objetos. Nada parece existir en esta habitación más que el tocador. Dos restricciones focales son las responsables de la centralidad icónica del tocador. Por una parte, la oscuridad circundante obliga a los ojos de Pip, deslumbrados por la luz, a focalizar el tocador como centro luminoso y, literalmente, a no ver lo que hay en el entorno; por otra parte, en tanto que la descripción está focalizada en el yo-narrado y no en el yoque-narra, la limitación cognitiva es responsable del alto grado de indeterminación en la descripción del amueblado de la habitación: como Pip no conoce los nombres ni los usos de los muebles que ve, el descriptor-narrador no los menciona, haciendo así extensiva esta restricción cognitiva al propio lector. Nosotros lectores tampoco sabemos qué otros muebles había. Pero lo realmente interesante es el equivalente, la transposición de experiencia en lenguaje, pues si para Pip la impresión es vaga por ignorancia, para nosotros lectores lo es por abstracción: el término genérico "furniture" nos impide ver cada uno de esos muebles con precisión.

Constantemente, el narrador adulto hace oír su voz en la preocupación que tiene por entender la experiencia de enton- 
ces y por hacer de esa experiencia algo inteligible y creíble para el lector. Pip, narrador adulto, reflexiona en el hecho de que el tocador estuviera en el primer plano de su percepción infantil y lo adjudica a su fascinación por Miss Havisham, fascinación provocada tanto por lo ex-céntrico como por lo absolutamente "central" de la organización social en clases (es notable la insistencia en el calificativo "fine", distinguido). ${ }^{14}$

En el tercer párrafo se inicia lo que podríamos llamar la pintura monocromática de un cuadro en "blanco mayor". La organización semántica insiste en el sema /blancura/ contenido en casi todos los términos que la componen. No sólo en aquellos calificados de manera explícita con el adjetivo blanco(a) ("white"), sino en aquellos que lo incluyen en su constitución semántica: los azahares y el encaje, por ejemplo. Otros que no contienen el sema de manera inherente, lo adquieren de manera aferente; por ejemplo, el pañuelo y los guantes, por contigüidad con el vestido de novia, no pueden sino visualizarse como blancos.

Implícita en la blancura que domina esta primera parte de la descripción está la significación de brillo y deslumbramiento que la siguiente secuencia activa al insistir en las alhajas relucientes. Y en este marco de esplendor, la creciente impresión de urgencia, de acción en proceso y, por ende, de cambio: el velo sin arreglar, el zapato en la mano como un gesto que connota la inminencia de la boda; las joyas regando su luz en el desorden del tocador; las maletas a medio empacar... Pero aun en este momento, que bien podríamos llamar el momento eufórico de la descripción, se oye una nota disonante que perturba el esplendor y la esperanza generados por la imagen proyectada: todo es blanco, sí, ¡incluso la cabellera de la novia!

14 Esta importante marca semántica se pierde en la traducción. Desgraciadamente, el traductor ha elegido el significado menos adecuado para calificar a Miss Havisham: "hermosa". Nadie más lejos de la hermosura que esta grotesca figura. 
En el último párrafo un vuelco magistral pone literalmente en movimiento a toda la descripción. El movimiento, sin embargo, no es del orden de lo mimético, sino que se produce por medios puramente retóricos. La estrategia textual es la repetición modulada: se vuelve a describir lo mismo que había sido descrito en blanco y resplandeciente, sólo que ahora lo es en amarillo y opaco; aquello que había sido urgencia se torna ahora en una impresión de movimiento paralizado que congela al tiempo. Nuevamente el narrador adulto reflexiona sobre la experiencia; concede lo imposible que es percibir de golpe todo aquello que acaba de describir y sin embargo insiste en que el niño vio más de lo que uno podría suponer. A pesar de esta reflexión que desplaza la perspectiva del yo-narrado al yo-que-narra, el movimiento de la descripción es ya tan vertiginoso que es la perspectiva del niño la que domina aunque el narrador adulto reflexione sobre la experiencia, y aunque sea él, de manera muy evidente, y no el niño, quien de hecho organice el equivalente verbal de la experiencia. Así, todo aquello que había sido caracterizado como blanco es ahora amarillo. Aun aquellos términos que no contienen de manera explícita una referencia al color, por la presión semántica lo adquieren: términos tales como marchito, o la carne que se enjuta y que remite a lo amarillo de la carnemomia. Las piedras preciosas pierden su fulgor, asimilándose así, en luz y color, a la amarillenta luz de las velas de cera que inaugura esta descripción, y que ahora, por esta degradación de la luz, tenemos la impresión de que se ha debilitado. Así, en la "repetición", el blanco se torna amarillo, lo lleno se enjuta, la luz se debilita hasta no habitar más que la cuenca de los ojos de Miss Havisham; el centellear de las joyas se torna opaco y la acción en proceso se congela para degradarse en una lenta corrupción de la carne.

Más aún, el impacto de la experiencia en el niño lo remite a su propio pasado: el recuerdo de una figura de cera y de una momia, experiencia personal que se aviva en su recuerdo para 
tratar de significar su experiencia; al mismo tiempo, el recuerdo se exterioriza en el símbolo de mortalidad y corrupción que anima el desarrollo de toda esta novela: momia y cuerpo de cera como figuración de la muerte y la degradación, imágenes en segunda potencia que resignifican, de manera retórica, la experiencia sensorial directa y la incorporan a la vida afectiva de Pip, “diagramándola", por así decirlo, en su cuerpo. "Lo imaginario está mucho más cerca y mucho más lejos de lo actual: más cerca por ser el diagrama de su vida en mi cuerpo, su pulpa o su revés carnal por primera vez expuestos a las miradas" $(1986,20) .{ }^{15}$

Pero hay más en el efecto de sentido que produce esta descripción. Es a todas luces evidente que la organización descriptiva no pretende ser realista de manera ingenua o directa; es decir, no pretende crear la ilusión de inmediatez, de que, paso a paso, ésta es la manera en que el niño percibió las cosas. Dicho de otro modo, el niño no vio a Miss Havisham dos veces, una en blanco y la otra en amarillo, tal y como está dada la secuencia textual. La organización semántica y retórica de este pasaje, a cargo del narrador-descriptor adulto, resulta más bien en un equivalente verbal de la experiencia del niño para el lector. Y es que la repetición imprime al texto un peculiar movimiento semántico que le permite al lector experimentar, antes que reflexionar, el cambio, el tiempo que pasa y el proceso de deterioro, aunado a la paradójica impresión de acción congelada. En la repetición, la degradación como tema, que orienta no sólo este fragmento sino la totalidad de la novela, da paso a la (de-)gradación como figura de la retórica que multiplica y refleja la degradación como tema. Son evidentes, entre otras, las gradaciones a) cromática: del blanco al amarillo, b) fotométrica: del fulgor de las piedras preciosas a

15 "L'imaginaire est beaucoup plus près et beaucoup plus loin de l'actuel: plus près puisqu'il est le diagramme de sa vie dans mon corps, sa pulpe ou son envers charnel pour la première fois exposés aux regards" $(1964,24)$. 
la opacidad, al deslustre de las cosas gastadas, c) dinámica: de la acción a la parálisis, y d) vital: de lo pleno a lo marchito, lo ajado y lo enjuto.

Cualidad, luz, color, profundidad, que están ahí ante nosotros, están ahí porque despiertan un eco en nuestro cuerpo, porque éste los recibe. Este equivalente interno, esta fórmula carnal de su presencia que las cosas suscitan en mí, ¿por qué a su vez no podrían suscitar un trazado, también visible, en el que cualquiera otra mirada encontrara los motivos que sostienen su inspección del mundo? Entonces aparece un visible a la segunda potencia, esencia carnal o icono del primero. ${ }^{16}$

Reflexionemos un momento sobre las posibles correspondencias de estas formas de lo visible con el relato. Primeramente parecería arbitrario - incluso ingenuo - transponer la reflexión del filósofo del dominio de lo visual al dominio de lo verbal. Pero es innegable que el lenguaje, como bien lo ha observado Greimas (1979, “iconicité”), tiene una dimensión icónica en la constitución semántica de ciertos lexemas investidos de semas particularizantes que son los que generan un efecto de sentido de orden sensorial. Este importante fenómeno de la particularización semántica, o iconización, se repite en ciertas formas discursivas, y de manera muy especial en la descripción. ${ }^{17}$ Por otra parte, la proyección de mundos ficcionales torna al lenguaje en un universo de discurso cuya significación también es del orden de lo sensible.

En la descripción de Dickens, la experiencia directa del niño lo lleva a activar una imagen, surgida de su propia histo-

16 “Qualité, lumière, couleur, profondeur, qui sont là-bas devant nous, n’y sont que parce qu'elles, veillent un écho dans notre corps, parce qu'il leur fait accueil. Cet équivalent interne, cette formule charnelle de leur présence que les choses suscitent en moi, pourquoi à leur tour ne susciteraient-ils pas un tracé, visible encore, où tout autre regard retrouvera les motifs qui soutiennent son inspection du monde? Alors paraît un visible à la deuxième puissance, essence charnelle ou icône du premier" (1964, 22).

${ }^{17}$ Cf. Luz Aurora Pimentel , "Configuraciones descriptivas”, en 2001, 72-88. 
ria, que entra en relación analógica con lo que en ese momento percibe. La imagen sintética momia/figura de cera se convierte así, para él, en "un visible a la segunda potencia" que dibuja, con trazos del pasado, la experiencia del presente en su propio cuerpo, y es por ese correlato carnal que el niño incorpora el mundo percibido. De este modo, el recuerdo - con su carga de alteridad espacial y temporal - irrumpe en la habitación de Miss Havisham para "diagramarla”, para sobreponer una significación imaginaria mucho más intensa que el mero instante presente: novia-momia atrapada en la parálisis de la cera de su propia desesperanza.

Ahora bien, ese "visible" podría de hecho extenderse a los demás sentidos, un sensible a la segunda potencia que es justamente lo que ocurre con el equivalente verbal propuesto por la descripción. Porque el efecto de la experiencia no se restringe solamente al personaje focal sino que se prolonga, transfigurado, en el lector. En él podría caracterizarse casi como un visible y un sensible a la tercera potencia, pues es notable el efecto dinámico que produce la organización semántica y retórica de esta extraña descripción estereoscópica, que además se desdobla en el tiempo. Esta inusitada experiencia de movimiento provocada por medios semánticos (el juego de la recurrencia de ciertos semas de blancura y luminosidad en oposición a semas de declive y opacidad, o el contraste entre isotopías tonales, etc.) y retóricos (la repetición modulada y la gradación como figuras de la retórica) opera en el lector como un trazo, "un diagrama de su vida en [su] cuerpo" y en su imaginación; un equivalente sensorial, producido por las relaciones semánticas propuestas por el texto, de lo que ya para Pip había sido equivalente icónico.

Así pues, esta descripción de Dickens se nos presenta como una experiencia sensible en segunda y tercera potencias, ya que se multiplica dentro y fuera del mundo ficcional. Dentro porque el niño la hace suya al asimilarla a su propio pasado; 
fuera porque gracias a la mediación del narrador, la sola organización semántica y retórica de la descripción transpone la experiencia del niño para evocar en el lector una experiencia verbal - y por ende significante- del devenir del tiempo, una experiencia que es, además, del orden de lo sensible, incluso de lo kinésico.

En resumen, podríamos hacer hincapié en el hecho de que la proyección narrativa del mundo es siempre una redescripción mediada por el filtro de un punto de vista sobre el mundo que imprime su propia subjetividad en el objeto representado. Menos evidente en la narración autoral, pues el sujeto de la mediación trata de ocultarse tras modelos de conocimiento extratextuales y formas de percepción altamente codificadas. Pero incluso en ese caso, como lo hemos visto en el texto de Balzac, el sujeto de la enunciación se traiciona en el sistema de valores que él atribuye - como algo "universalmente" aceptado - al objeto descrito. No obstante, la obsesión realista desemboca inesperadamente en una doble mediación, pues ya el mundo representado está mediado por los modelos de conocimiento "autorizados" a los que se recurre para organizar la descripción; a esto habría que añadir la otra fuente de mediación: la subjetividad del narrador-descriptor aun cuando se oculte tras la ilusión de objetividad encarnada por la autoridad de códigos culturales compartidos — una objetividad de consenso- En narración figural, en cambio, el narrador, en tanto que sujeto de la mediación por enunciación, abiertamente duplica la mediación al proponer otra conciencia como el punto de vista desde el cual se mira y representa el mundo. Doble mediación, entonces, aunque diferente de la autoral, pues en narración figural la doble mediación es inherente a esta forma narrativa; porque si narrar es ya mediar entre el lector y el mundo, focalizar es volver a filtrar ese mundo narrado, enrareciéndolo e intensificando así la impresión de subjetividad, de visión individual, única. 


\section{Obras citadas}

Balzac, Honoré de, Les illusions perdues, Paris, Flammarion, 1966.

—, La comedia humana (trad. Aurelio Garzón del Camino), Las ilusiones perdidas, México, Col. Málaga, Vol.VII, 1956.

Barthes, Roland, S/Z, Paris, Seuil, 1970.

Dickens, Charles, Grandes esperanzas, Obras completas, tomo II [trad.] José Méndez Herrera, Madrid, Aguilar, 1962.

-, Great Expectations, London, Panther Books, 1964.

Eco, Umberto, Lector in fabula, Lumen, Barcelona, 1981.

Foucault, Michel, Les mots et les choses. Une archéologie des sciences humaines, Paris, Gallimard, 1966.

Genette, Gérard, "Discours du récit", en Figures III, Paris, Seuil, 1972.

—, Nouveau discours du récit, Paris, Seuil, 1983.

Greimas, A. J., Sémiotique. Dictionnaire raisonné de la théorie du langage, Paris, Hachette, 1979.

Hamon, Philippe, “Qu'est-ce qu'une description?", Poétique, 2, Paris, Seuil, 1972.

—, Introduction à l'analyse du descriptif, Paris, Hachette, 1981.

Merleau-Ponty, Maurice, Phénoménologie de la perception, Paris, Gallimard, 1945.

—, L'oeil et l'esprit, Paris, Gallimard, "Folio", 1964.

—, El ojo y el espíritu [trad.] Jorge Romero Brest, Barcelona, Paidós, 1986.

Pimentel, Luz Aurora, El espacio en la ficción / Ficciones espaciales, México, Siglo XXI / unAm, 2001.

Ricoeur, Paul, Hermeneutics and the Human Sciences. Essays on Language and Interpretation, trad. John B. Thompson, Cambridge, Cambridge University Press \& Éditions de la Maison des Sciences de l'Homme, Paris, 1981.

—, La métaphore vive, Paris, Seuil, 1975.

Stanzel, Franz K., A Theory of Narrative, trad. Charlotte Goedsche, Cambridge, Cambridge University Press, 1984. 
Todorov, Tzvetan, “Qu'est-ce que le structuralisme?”, Poétique, 2, Paris, Seuil, 1968.

WeIsBerg, Jean, L'espace romanesque, Lausanne, L'Âge d'Homme, 1978.

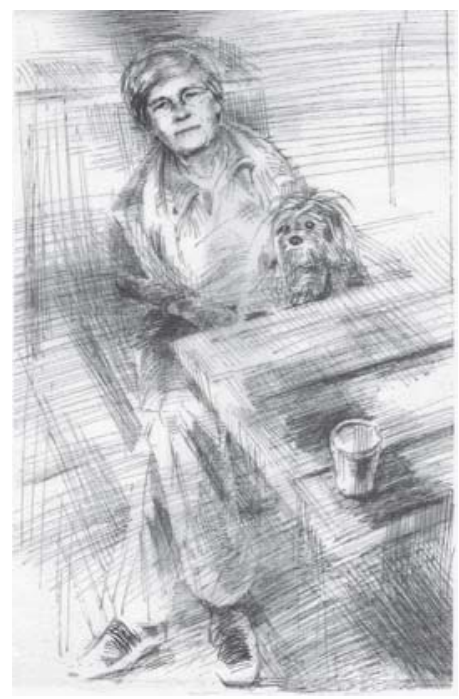


